Situs Jurnal : $\underline{\text { http://ejurnal.stiepancasetia.ac.id/index.php/jieb }}$

Jilid 4 Nomor 1 Maret 2018

Hal $069-076$

\title{
PENGARUH GAYA KEPEMIMPINAN DAN MOTIVASI KERJA TERHADAP DISIPLIN KERJA KARYAWAN TREEPARK HOTEL BANJARMASIN (STUDI KASUS PADA INTRO BISTRO)
}

\begin{abstract}
Nurul Hasanah*
Abstract: This research discusses how human resources in organization activity at company one of them hotel business at Treepark Hotel in order to survive in face of competition and market demand. This research is a quantitative research that is explanatory research that is research to test hypothesis among variables. The population in this study is all employees at the Intro Bistro Bistro Treepark Hotel Banjarmasin which amounted to 35 people. The result of the research found that leadership style have positive effect to employee work discipline, while work motivation has no effect to employee's work discipline, and simultaneously leadership style and work motivation have an effect on employee work discipline.
\end{abstract}

Keywords: leadership style, work motivation, work discipline, intro bistro

Abstrak: Penelitian ini membahas bagaimana sumber daya manusia dalam kegiatan organisasi pada perusahaan salah satunya bisnis perhotelan pada Treepark Hotel agar mampu bertahan dalam menghadapi persaingan dan tuntutan pasar. Penelitian ini merupakan penelitian kuantitatif yang bersifat penelitian eksplanatory yaitu penelitian untuk menguji hipotesis antar variabel. Populasi pada penelitian ini adalah seluruh karyawan pada bagian restoran Intro Bistro Treepark Hotel Banjarmasin yang berjumlah 35 orang. Hasil penelitian menemukan bahwa gaya kepemimpinan berpengaruh positif terhadap disiplin kerja karyawan, sedangkan motivasi kerja tidak berpengaruh terhadap disiplin kerja karyawan, dan secara simultan gaya kepemimpinan dan motivasi kerja besama-sama berpengaruh terhadap disiplin kerja karyawan.

Kata kunci : gaya kepemimpinan, motivasi kerja, disiplin kerja, intro bistro

\section{Latar Belakang}

Dalam meraih keunggulan bersaing, sebuah hotel tidak hanya harus memiliki inovasi dalam pengembangan produk, tetapi juga harus menjamin kualitas sumber daya yang dimiliki agar dapat memberikan pelayanan yang memuaskan bagi para pelanggan maupun calon pelanggannya. Agar dapat meningkatkan kualitas sumber daya manusia perusahaan harus memiliki pengelolaan yang baik terhadap karyawannya. Pengelolaan tersebut seharusnya didukung oleh kedisiplinan karyawan dalam mengikuti aturan - aturan maupun program program pengembangan dan pengelolaan sumber daya manusia yang telah ditetapkan oleh perusahaan.

Disiplin memberikan peranan yang sangat besar dalam menunjukkan tingkat kinerja karyawan agar perusahaan dapat mencapai tujuan yang telah ditetapkan. Dalam penegakan disiplin tentu seorang pemimpin memiliki peranan yang sangat penting. Pemimpin merupakan orang - orang yang memiliki keahlian atau kemampuan untuk dapat mempengaruhi orang lain agar dapat melakukan sesuatu sesuai dengan keinginannya dan tujuan yang ingin dicapai. 
Kepemimpinan pada hakikatnya diartikan sebagai suatu ilmu sekaligus seni yang dimiliki seseorang untuk mempengaruhi orang lain dalam mencapai tujuan yang telah ditentukan. Kepemimpinan bukan hanya berkaitan dengan mempengaruhi dalam mencapai tujuan melainkan merupakan suatu proses memotivasi tingkah laku karyawan atau anggota organisasi, serta mempengaruhi dalam upaya perbaikan kelompok serta disiplin kerja dari karyawan perusahaan. Disiplin tidak hanya dipengaruhi oleh satu faktor saja yaitu gaya kepemimpinan melaikan juga dipengaruhi oleh faktor lain salah satunya motivasi (Martoyo dalam Ida Ayu 2014). Motivasi merupakan pendorong seseorang untuk melakukan pekerjaannya dengan baik. Apabila seseorang termotivasi maka mereka akan membuat sebuah pilihan positif utuk melakukan sesuatu karena dapat memuaskan keinginan mereka. Motivasi dapat memacu seorang karyawan untuk bekerja keras dalam rangka pencapaian tujuan.

Terkait dengan masalah gaya kepemimpinan, motivasi, serta disiplin karyawan maka perhotelan merupakan salah satu sektor yang tepat untuk menginterpretasikan permasalahan tersebut. Hotel merupakan salah satu penggerak perekonomian yang memiliki peranan penting dalam perkembangan ekonomi suatu masyarakat. Pangsa pasar hotel yang dulunya terfokus pada penjualan kamar kini telah melebar menjadi hotel yang juga mampu bersaing di sektor lain seperti menyewakan ballroom untuk keperluan acara seminar, menyangkut urusan keuangan hotel menyediakan penukaran valuta asing, menyediakan cafetaria dan restoran, serta menyediakan sarana hiburan seperti band dan penyanyi serta lebih memanfaatkan sarana kolam renang dan tempat fitnes untuk dijual sebagai produk hotel di masyarakat. Dalam menghadapi banyak hotel pesaing, TreePark Hotel dituntut untuk bekerja keras demi mempertahankan eksistensi serta menarik perhatian pelanggan lebih banyak lagi. Pencapaian target perusahaan yaitu menghimpun pelanggan sebanyak - banyaknya dari masyarakat serta mengoptimalkan fasilitas hotel lainnya tentunya harus didukung sepenuhnya oleh pencapaian yang tinggi dari kinerja karyawannya. Kinerja karyawan sangat bergantung kepada sejauh mana disiplin yang telah dilakukan oleh karyawan TreePark Hotel dalam melakukan pekerjaannya. TreePark Hotel Banjarmasin merupakan salah satu cabang dari TreePark Hotel yang sedang berusaha meningkatkan kinerja karyawannya dalam rangka pencapaian tujuan perusahaan terutama pada bagian Food\&Baverage service. Jumlah karyawan TreePark Hotel Banjarmasin pada bagian F\&B sebanyak 35 orang. Disiplin kerja karyawan dinilai berdasarkan ketepatan jam kerja, kepatuhan terhadap peraturan, serta tingkat absensi. Pada tahun 2017 jumlah karyawan yang tidak hadir tanpa keterangan masih banyak. Puncaknya adalah pada bulan Juni sampai Agustus. Hal tersebut terjadi karena ada karyawan yang tidak mengirimkan surat keterangan sakit sehingga dianggap tidak hadir tanpa keterangan.

\section{Kajian Literatur}

Menurut Hasibuan (2007) kepemimpinan adalah proses mempengaruhi orang lain untuk memahami dan setuju tentang apa yang akan dikerjakan dan bagaimana tugas itu dapat dilakukan secara efektif, dan proses memfasilitasi usaha individu dan kelompok untuk mencapai tujuan bersama. Mulyadi dan Veithzal Rivai (2009) menerangkan bahwa gaya kepemimpinan merupakan pola perilaku dan strategi yang disukai dan gaya kepemimpinan adalah pola tingkah laku yang dirancang sedemikian rupa untuk mengintegrasikan sering diterapkan oleh seorang pemimpin dalam rangka mencapai sasaran organisasi.

Motivasi merupakan alur yang menerangkan segala sesuatu mengenai intensitas, arah, dan ketekunan seseorang dalam meraih apa yang menjadi tujuannya (Robbins, 2007). Dalam penelitian ini teori yang digunakan adalah Hirearki Teori Kebutuhan. Hierarki kebutuhan merupakan teori yang dimiliki oleh Abraham Maslow. Maslow menyatakan dalam diri seseorang terdapat hierarki dari lima kebutuhan. (Rivai, 2011). (1) Fisiologi yaitu meliputi rasa haus, lapar, berlindung, dan sebagainya (2) Rasa Aman yaitu meliputi perlindungan terhadap 
bahaya secara fisik (3) Sosial meliputi hubungan personal, masyarakat, kasih sayang, dan sebagainya (4) Penghargaan (5) Aktualisasi diri yaitu kemauan untuk menjadi seseorang yang menguasai atau ahi dalam bidang tertentu.

Disiplin kerja ialah suatu alat atau cara yang digunakan suatu perusahaan untuk mempengaruhi tingkah laku karyawannya agar taat terhadap ketentuan dan aturan dalam perusahaan untuk mencapai tujuan yang dimiliki perusahaan (Rivai, 2009) Banyak pendapat ahli yang menguraikan tentang faktor - faktor yang dapat mempengaruhi disiplin kerja seseorang. Hasibuan (2007) menyatakan bahwa ada beberapa faktor yang berpengaruh terhadap kedisiplinan karyawan yakni balas jasa, tujuan dan kemampuan, keadilan, sanksi hukum, ketegasan dan hubungan kemanusiaan, serta teladan kepemimpinan. Menurut Edy Sutrisno dalam Tintami (2012) ada beberapa indikator disiplin kerja yakni besarnya kompensasi, keteladanan pemimpin dalam perusahaan, aturan pasti perusahaan, keberanian pemimpin dalam pengambilan keputusan maupun tindakan, pengawasan pimpinan, perhatian pemimpin pada karyawannya, serta tindakan - tindakan penegakan disiplin.

Berdasarkan pada latar belakang, serangkaian teori dan penelitian terdahulu yang telah dikemukakan, maka dapat dirumuskan hipotesis yang ingin diuji pada penelitian ini sebagai beirkut:

Ho1 : $\beta=0$; tidak terdapat pengaruh yang signifikan secara parsial antara gaya kepemimpinan terhadap disiplin kerja karyawan.

Ha1 : $\beta \neq 0$; terdapat pengaruh yang siginfikan secara parsial antara gaya kepemimpinan terhadap disiplin kerja karyawan

Ho : $\beta=0$; tidak terdapat pengaruh yang signifikan secara parsial antara motivasi terhadap disiplin kerja karyawan.

Ha : $\beta \neq 0$; terdapat pengaruh yang siginfikan secara parsial antara Motivasi terhadap disiplin kerja karyawan

\section{Metode Penelitian}

Penelitian ini bersifat sebagai penelitian penjelasan (explanatory research). Dalam penelitian ini peneliti ingin menguji pengaruh secara parsial dan simultan gaya kepemimpinan dan motivasi kerja terhadap disiplin kerja karyawan Treepark Hotel Banjarmasin (studi kasus Intro Bistro). Dalam penelitian ini teknik penentuan sampel menggunakan sampel jenuh sebanyak 35 orang. Sampel jenuh menurut Sugiyono (2008) adalah teknik penentuan sampel bila semua anggota populasi digunakan sebagai sampel. Dalam penelitian ini penentuan sampel jenuh dilakukan agar membuat generalisasi dengan kesalahan yang sangat kecil.

Uji instrumen dalam penelitian ini meliputi Uji Validitas dan Uji Reliabilitas. Selanjutnya dilakukan Uji Asumsi Klasik yang terdiri dari Uji Normalitas, Uji Multikolinearitas, dan Uji Heteroskedastisitas. Langkah terakhir adalah Analisis Regresi Berganda. Bentuk regresi linear berganda adalah:

$\mathrm{Y}=\mathrm{a}+\mathrm{b} 1 \mathrm{X} 1+\mathrm{b} 2 \mathrm{X} 2+\mathrm{e}$

Pengujian Hipotesis

1. Uji Hipotesis (Uji t/pengujian hipotesis secara parsial)

2. Uji Hipotesis(Uji F/uji hipotesis secara simultan)

3. Koefisien Determinasi $\left(\mathrm{R}^{2}\right)$ 


\section{Hasil Penelitian dan Pembahasan}

Penelitian dilakukan dengan jumlah responden sebanyak 35 orang karyawan. Analisis data dimulai dengan melakukan uji validitas dan uji reliabilitas instrumen. Hasil pengujian menunjukkan bahwa semua data yang digunakan dalam penelitian ini dinyatakan valid dan reliabel. Ini artinya data yang digunakan dalam penelitian ini tidak bermakna ganda dan sesuai dengan apa yang ingin diukur.

Hasil deskripsi variabel menunjukkan bahwa pada Treepark Hotel Banjarmasin (studi kasus Intro Bistro), dari usur yang diteliti yaitu gaya kepemimpinan, motivasi kerja, dan disiplin kerja karyawan memiliki rata-rata penilaian masing-masing variabel menunjukkan nilai diatas 3. Temuan awal ini memperkuat dugaan bahwa dengan gaya kepemimpinan dan motivasi kerja yang baik dapat meingkatkan pula disiplin kerja karyawan. Selengkapnya dapat dilihat dari uji asumsi klasik, analisis regresi berganda dan pengujian hipotesis.

Berdasarkan data dalam tabel 1 menunjukkan bahwa nilai VIF masing-masing variabel bebas lebih kecil dari 10, sehingga dapat dikatakan tidak terjadi gejala multikolinearitas.

1. Uji Heterokedastisitas

Model regresi yang baik adalah tidak terjadi heterokedastisitas. Untuk mendeteksi ada tidaknya heterokedastisitas dapat digunakan metode grafik Scatterplot yang dihasilkan dari output program SPSS versi 21, Apabila pada gambar menunjukkan bahwa titik-titik menyebar secara acak serta tersebar baik diatas maupun di bawah angka 0 pada sumbu Y, maka hal ini dapat disimpulkan tidak terjadi adanya heterokedastisitas pada model regresi (Ghozali,2005). Hasil uji homoskedastisitas (atau tidak adanya gejala heteroskedastisitas). Berdasarkan hasil uji heteroskedastisitas metode grafik scatterplot menunjukkan bahwa sebaran data penelitian cenderung menyebar tidak teratur dan tidak membentuk pola tertentu. Hal ini berarti tidak terjadi penyimpangan asumsi klasik heterokedastisitas pada model regresi yang dibuat, dengan kata lain menerima hipotesis homoskedastisitas (Gambar 1).

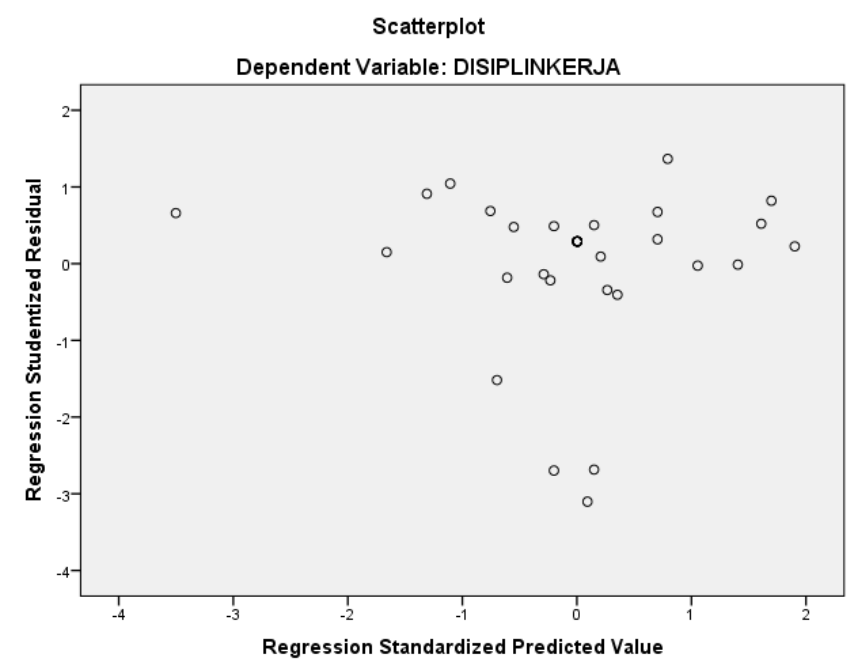

Gambar 1. Hasil Uji Heterokedastisitas

2. Uji Normalitas

Uji Normalitas bertujuan untuk menguji apakah dalam model regresi, variabel bebas dan variabel terikat, keduanya terdistribusikan secara normal ataukah tidak. Dari gambar 2 tersebut terlihat bahwa sebaran jawaban responden terdistribusi secara normal. Grafik 
histogram sebagaimana dalam Gambar 2 menunjukkan bahwa bentuk grafik seperti lonceng terbalik. Hal tersebut menunjukkan distribusi data penelitian berdistribusi normal. Grafik normal P-P Plot menunjukkan sebaran data menyebar di sekitar garis diagonal. Hal tersebut menunjukkan distribusi data penelitian berdistribusi normal.

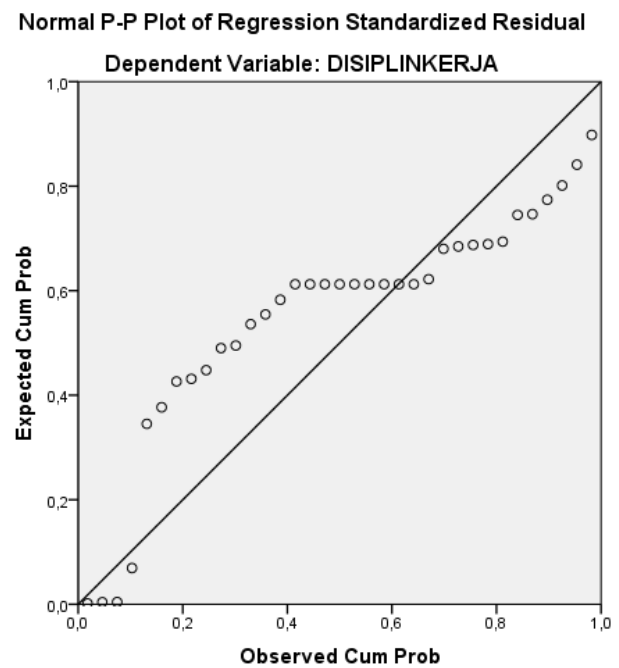

Gambar 2. Hasil Uji Normalitas

Tabel 1. Hasil Estimasi Regresi

\begin{tabular}{|c|c|c|c|c|c|c|}
\hline \multicolumn{7}{|c|}{ Coefficients $^{\mathrm{a}}$} \\
\hline \multirow{2}{*}{\multicolumn{2}{|c|}{ Model }} & \multicolumn{2}{|c|}{$\begin{array}{l}\text { Unstandardized } \\
\text { Coefficients }\end{array}$} & $\begin{array}{l}\text { Standardized } \\
\text { Coefficients }\end{array}$ & \multirow[t]{2}{*}{$\mathrm{t}$} & \multirow[t]{2}{*}{ Sig. } \\
\hline & & B & Std. Error & Beta & & \\
\hline \multirow[t]{3}{*}{1} & (Constant) & & 8,516 & &,- 825 & ,415 \\
\hline & CAYA KED & 7,026 & & & & \\
\hline & $\begin{array}{l}\text { GAYAKEPEMIMPINAN } \\
\text { MOTIVASI }\end{array}$ & $\frac{, 964}{561}$ & $\frac{175}{.313}$ & $\frac{.705}{229}$ & $\frac{5,516}{1,792}$ & $\begin{array}{l}, 000 \\
, 083\end{array}$ \\
\hline
\end{tabular}

Berdasarkan hasil analisis regresi linear berganda pada Tabel 1 dapat diketahui persamaan regresi yang terbentuk sebagai berikut:

$Y=-7,026+0,964 X 1+0,561 X 2$

Keterangan:

$\mathrm{Y}=$ Disiplin Kerja

$\mathrm{X} 1$ = Gaya Kepemimpinan

$\mathrm{X} 2$ = Motivasi

1. Nilai constant $(\mathrm{Y})$ sebesar $-7,026$ artinya jika variabel gaya kepemimpinan dan motivasi bernilai 0 (nol), maka nilai variabel disiplin kerja (Y) akan berada pada angka -7,026.

2. Koefisien regresi X1 (gaya kepemimpinan) dari perhitungan nilai berganda didapat nilai coefficients sebesar 0,964 , yang artinya jika gaya kepemimpinan mengalami kenaikan 
sebesar 1\% maka volume disiplin kerja karyawan akan mengalami kenaikan sebesar 96,4\%. Dan karena koefisiennya bernilai positif maka terdapat hubungan yang positif antara gaya kepemimpinan dengan disiplin kerja karyawan.

3. Koefisien regresi X2 (motivasi kerja) dari perhitungan nilai berganda didapat nilai coefficients sebesar 0,561 yang artinya jika motivasi kerja mengalami kenaikan sebesar $1 \%$ maka volume disiplin kerja karyawan akan mengalami kenaikan sebesar 56,1\%. Dan karena koefisiennya bernilai positif maka terdapat hubungan yang positif antara motivasi kerja dengan disiplin kerja karyawan.

Uji t dimaksudkan untuk mengetahui signifikansi pengaruh secara parsial dari variabelvariabel bebas $(\mathrm{X})$ terhadap variabel tergantung (Y). Hasil uji hipotesis dengan bantuan salah satu program statistik disajikan dalam Tabel 1. Berdasarkan data pada Tabel 1 dapat disimpulkan bahwa dari nilai thitung ditunjukkan bahwa:

\section{Uji Hipotesis 1 (H1)}

Perumusan hipotesis:

Ho : $\beta=0$; tidak terdapat pengaruh yang signifikan secara parsial antara gaya kepemimpinan terhadap disiplin kerja karyawan.

Ha $: \beta \neq 0$; terdapat pengaruh yang siginfikan secara parsial antara gaya kepemimpinan terhadap disiplin kerja karyawan

Dari tabel 1 bahwa variabel gaya kepemimpinan $\left(\mathrm{X}_{1}\right)$ memiliki nilai $\mathrm{t}_{\text {hitung }}$ sebesar 5,516 lebih besar dari nilai tabel sebesar 2,002 $(\mathrm{df}=\mathrm{n}-2)$. Hal tersebut dipertegas dengan nilai probabilitas sebesar 0,000 lebih kecil dari 0,05 sebagai taraf yang telah ditetapkan. Hasil uji statistik tersebut menunjukkan bahwa Hipotesis diterima yang berarti secara parsial variabel gaya kepemimpinan $\left(\mathrm{X}_{1}\right)$ berpengaruh signifikan terhadap disiplin kerja karyawan $(\mathrm{Y})$.

2. Uji Hipotesis $2(\mathrm{H} 2)$

Perumusan hipotesis:

Ho : $\beta=0$; tidak terdapat pengaruh yang signifikan secara parsial antara motivasi terhadap disiplin kerja karyawan.

Ha $: \beta \neq 0$; terdapat pengaruh yang siginfikan secara parsial antara Motivasi terhadap disiplin kerja karyawan

Dari tabel 1 bahwa motivasi kerja $\left(\mathrm{X}_{2}\right)$ memiliki nilai thitung sebesar 1,792 lebih kecil dari nilai $t_{\text {tabel }}$ sebesar 2,002 $(\mathrm{df}=\mathrm{n}-2)$. Hal tersebut dipertegas dengan nilai probabilitas sebesar 0,083 lebih besar dari 0,05 sebagai taraf yang telah ditetapkan. Hasil uji statistik tersebut menunjukkan bahwa secara parsial variabel motivasi kerja $\left(\mathrm{X}_{2}\right)$ tidak berpengaruh signifikan terhadap disiplin kerja karyawan (Y).

Analisis selanjutnya adalah uji F, yaitu untuk menguji pengaruh gaya kepemimpinan dan kompensasi berpengaruh signifikan terhadap kinerja karyawan. Hasil uji hipotesis dengan bantuan salah satu program statistik disajikan dalam Tabel 2 . 
Tabel 2. Hasil Uji F (Simultan)

\begin{tabular}{llcrrrr}
\hline Model & \multicolumn{5}{c}{ ANOVA $^{\mathbf{a}}$} \\
\hline \multirow{2}{*}{1} & $\begin{array}{c}\text { Sum of } \\
\text { Squares }\end{array}$ & Df & $\begin{array}{c}\text { Mean } \\
\text { Square }\end{array}$ & F & Sig. \\
\cline { 2 - 7 } & Regression & 256,999 & 2 & 128,500 & 15,577 &, $000^{\mathrm{b}}$ \\
\cline { 2 - 7 } & Residual & 263,972 & 32 & 8,249 & & \\
\cline { 2 - 6 } & Total & 520,971 & 34 & & & \\
\hline \multicolumn{7}{l}{ a. Dependent Variable: DISIPLINKERJA } \\
\hline
\end{tabular}

Uji determinasi dilakukan untuk mengetahui besarnya pengaruh variabel gaya kepemimpinan, kompensasi dan efektivitas pelatihan terhadap kinerja karyawan. Uji determinasi dalam penelitian ini dapat dideteksi dengan nilai adjusted $R$ square yang dihasilkan oleh model regresi. Hasil uji determinasi disajikan dalam tabel 3.

Tabel 3. Hasil Uji Determinasi

\begin{tabular}{llllr}
\hline \multicolumn{5}{c}{ Model Summary } \\
\hline Model & $\mathrm{R}$ & R Square & Adjusted R Square & Std. Error of the Estimate \\
\hline 1 &, $702^{\mathrm{a}}$ &, 493 &, 462 & \\
\hline a. Predictors: (Constant), MOTIVASI, GAYAKEPEMIMPINAN & & \\
\hline
\end{tabular}

Berdasarkan perhitungan pada tabel 2 diketahui nilai $\mathrm{F}_{\text {hitung }}=15,577$ lebih besar dari nilai $\mathrm{F}_{\text {tabel }}$ yaitu sebesar $2,769\left(d f_{1}=2 ; d f_{2}=32 ; \alpha=5 \%\right)$. Hal tersebut juga ditunjukkan dengan nilai signifikansi yang dihasilkan yaitu sebesar 0,000 jauh lebih kecil dari 0,05 sebagai taraf yang telah ditetapkan. Hasil uji statistik tersebut berarti bahwa gaya kepemimpinan dan motivasi kerja berpengaruh signifikan terhadap disiplin kerja karyawan. Dengan demikian dapat dinyatakan bahwa Hipotesis dapat terbukti kebenarannya.

Berdasarkan data dalam Tabel 3 diketahui bahwa nilai adjusted $\mathrm{R}$ square sebesar 0,493 setara dengan $49,3 \%$. Hal tersebut berarti bahwa variabel bebas yang terdiri dari gaya kepemimpinan dan motivasi kerja memiliki pengaruh terhadap disiplin kerja karyawan sebesar 49,3\%. Hasil determinasi tersebut menunjukkan bahwa variabel bebas memiliki pengaruh terhadap variabel terikatnya sebesar $49,3 \%$, sedangkan sisanya yaitu sebesar 50,7\% dipengaruhi oleh variabel lain yang tidak dibahas dalam penelitian ini.

Berdasarkan hasil pengujian secara statistik dapat terlihat dengan jelas bahwa secara parsial (individu) hanya variabel bebas gaya kepemimpinan yang berpengaruh terhadap variabel terikat yaitu disiplin kerja. Pengaruh yang diberikan variabel bebas gaya kepemimpinan tersebut bersifat positif artinya semakin tinggi pengaruh gaya kepemimpinan maka mengakibatkan semakin tinggi pula disiplin kerja karyawan. Hasil tersebut sesuai dengan hipotesis yang telah diajukan. Hasil penelitian ini juga sesuai dengan penelitian sebelumnya.

\section{Kesimpulan}

Berdasarkan pada hasil dari penelitian ini dapat dirumuskan beberapa kesimpulan sebagai berikut:

1. Gaya kepemimpinan mempengaruhi disiplin kerja karyawan Treepark Hotel Banjarmasin

2. Motivasi Kerja mempengaruhi disiplin kerja karyawan Treepark Hotel Banjarmasin

Secara bersama-sama gaya kepemimpinan dan motivasi kerja yang diberikan perusahaan mempengaruhi disiplin kerja karyawan Treepark Hotel Banjarmasin. 


\section{DAFTAR PUSTAKA}

Alex S. Nitisemito, 2002, Manajemen Personalia: Manajemen Sumber Daya Manusia. Ghalia Indonesia, Jakarta.

Dessler, Garry. 2006. Manajemen Sumber Daya Manusia. Jakarta: Indeks.

Ghozali, Imam. 2005. Aplikasi Analisis Multivariate dengan Program SPSS.

Semarang: BP Universitas Diponegoro. Semarang

Hasibuan, Malayu SP, 2010. Manajemen Sumber Daya Manusia Edisi Revisi. Jakarta: Bumi Askam

Handoko, T. Hani, 2008. Manajemen Personalia dan Sumber Daya Manusia Edisi 2. Yogyakarta:BPFE

Ida Ayu Brahmasari. "Pengaruh Motivasi Kerja, Kepemimpinan dan Budaya Organisasi terhadap Kepuasan serta Dampaknya pada Kinerja Perusahaan (Studi Kasus pada PT. Pei Hai International Wiratama Indonesia”. Jurnal Manajemen dan Kewirausahaan. Vol. 10, No. 2 September 2008, 124-135

M. Kiswanto, "Pengaruh Kepemimpinan dan Komunikasi terhadap Kinerja Karyawan Kaltim Pos Samarinda" http://www.karyailmiah.polnes.ac.id Jurnal Eksis, Vol. 6 No. 1, Maret 2010, 1267-1439

Purwaningsih, R., 2007. Pegembangan Metode QuickExposure Checklist (QEC) untuk Menilai Postur Departemen Produksi (Studi Kasus pada Departemen Produksi Final Assy Car Line Holden PT. Semarang Auto Comp Manufacturing Indonesia). Prosiding Seminar nasional Ergonomi dan K32007; Semarang, 15-16 November 2007

Singgih Santoso, 2002. SPSS Statistik Parametrik. Cetakan Kedua. PT. Elek Media Komputindo. Jakarta

Sugiyono, 2008. Statistika untuk penelitian. Badung: Alfabeta 